\title{
LECTURA, ESCRITURA Y ORALIDAD EN PERFILES DE EGRESO DE EDUCACIÓN SUPERIOR: CONTRASTES ENTRE INSTITUCIONES Y CARRERAS $^{1}$
}

\author{
Federico Navarro², Natalia Ávila Reyes ${ }^{3}$, \\ Lina Calle-Arango ${ }^{4}$, Ana Cortés Lagos ${ }^{5}$
}

\begin{abstract}
RESUMEN
La llamada "sociedad del conocimiento" requiere escritores y oradores expertos, que participen en contextos ciudadanos, administrativos y profesionales complejos y dinámicos. Sin embargo, estudios previos sugieren que esta formación se relega al currículum oculto en educación superior. Este artículo busca identificar la presencia de la lectura, la escritura y la oralidad en algunos instrumentos curriculares clave del sistema de educación superior chileno. Se seleccionaron diez universidades con rasgos institucionales diferenciados y cinco carreras diversas; se recolectaron 50 perfiles de egreso públicos y diez modelos educativos; y se codificaron cualitativamente las competencias letradas implícitas y explícitas, junto con las concepciones subyacentes, con cuantificación posterior. Los resultados muestran que la lectura, la escritura y la oralidad aparecen invisibilizadas o con baja frecuencia y con una visión reproductiva y generalista en los perfiles de egreso universitarios chilenos, en particular en carreras como Pedagogía en Educación Básica. A partir de estos hallazgos, se sugiere que los procesos de innovación por competencias y acreditación de carreras e instituciones estén informados por una concepción contemporánea de la lectura, la escritura y la oralidad como competencias complejas, retóricas, epistémicas y disciplinarmente situadas, que requieren un lugar explícito y un compromiso institucional en la formación de profesionales.
\end{abstract}

Conceptos clave: concepciones, currículum, educación superior, escritura, innovación educativa, lectura, literacidad, oralidad, perfiles de egreso, requisitos de graduación.

1 Se agradece el financiamiento otorgado por el Consejo Nacional de Educación (Convocatoria CNED/2018), por el FONDECYT No 1191069 de ANID, por ANID/PIA/Fondos Basales para Centros de Excelencia FB0003 y por la Universidad de O'Higgins.

2 Universidad de O'Higgins, Rancagua, Chile. Contacto: navarro@uoh.cl

3 Pontificia Universidad Católica de Chile, Santiago, Chile. Contacto: naavila@uc.cl

4 Pontificia Universidad Católica de Chile, Santiago, Chile. Contacto: lcalle@uc.cl

5 Syracuse University, Siracusa, Estados Unidos. Contacto: ancortes@syr.edu 


\title{
READING, WRITING AND SPEAKING IN HIGHER EDUCATION GRADUATE PROFILES: CONTRASTS ACROSS INSTITUTIONS AND MAJORS
}

\begin{abstract}
The so-called knowledge societies are characterized by demands to participate in complex and dynamic forms of citizenship, administrative, and professional roles, which require expert writers and speakers. However, previous studies suggest that literacy is relegated to the hidden curriculum in higher education. This study aims to identify the presence of reading, writing, and speaking in curricular instruments central to higher education, in Chile. The research involved ten universities selected to represent a variety of institutional projects and five different majors, and 50 public graduate profiles and ten educational models were collected. Explicit and implicit allusions to literacy skills were qualitatively coded, together with underlying conceptions of literacy, and occurrences were quantified. Results show that reading, writing, and speaking are either hidden or infrequent, and depicted as reproductive, basic skills in graduate profiles in Chilean higher education, particularly in majors such as Pedagogy in Primary Education. These findings suggest that competency-based educational innovation and accreditation processes in higher education need to be revised to include updated understandings of reading, writing, and speaking as complex, epistemic, and situated rhetorical skills that require explicit teaching and institutional commitment for future graduates.
\end{abstract}

Key concepts: conceptions; curriculum; higher education; writing; educational innovation; reading; literacy; speaking; graduate profiles; graduation requirements. 
172 LECTURA, ESCRITURA Y ORALIDAD EN PERFILES DE EGRESO DE EDUCACIÓN SUPERIOR: CONTRASTES ENTRE INSTITUCIONES Y CARRERAS - F. Navarro, N. Ávila Reyes, L. Calle-Arango, A. Cortés Lagos

La denominada "sociedad de la información y el conocimiento" ofrece contextos y roles de participación ciudadana, administrativa y profesional flexibles, diversos, cambiantes, interdisciplinarios y colaborativos. Por este motivo, los graduados universitarios no solo deben conocer y utilizar los conocimientos específicos de sus espacios disciplinares, sino también poseer estrategias y habilidades para comprender críticamente nuevos ámbitos, identificar objetivos, cumplir creativamente funciones diversas, adecuarse a situaciones, negociar con distintos participantes, aprender nuevos contenidos y transferir sus conocimientos previos.

En educación superior, estas nuevas prácticas y demandas sociales han influido en procesos de innovación curricular con foco en las denominadas "competencias ${ }^{6}$ para el siglo XXI" (Reimers \& Chung, 2016), es decir, las formas de aprender, razonar, participar y comunicar, con alta demanda cognitiva, que permiten comprender, adecuarse, cumplir propósitos y transferir conocimientos y habilidades de manera crítica y reflexiva a situaciones nuevas y dinámicas (Kreber, 2009). Las innovaciones curriculares han impulsado que los programas y planes de estudios coloquen al estudiante y a su formación integral en el centro de la organización curricular (Lehesvuori, Ramnarain, \& Viiri, 2018); que se incluyan listas claras y articuladas de competencias a enseñar y evaluar; que se ajusten y expliciten los perfiles de egreso como contratos formativos tributarios de esas competencias; que se incorporen, modifiquen o excluyan asignaturas por criterios de incumbencia o de acreditación nacional e internacional; que se declaren, cuantifiquen y flexibilicen las trayectorias, espacios, fuentes y tiempos de estudio; que se fomenten formas de enseñanza, aprendizaje, participación y evaluación diversas; y que se establezcan puentes de intercambio y colaboración entre unidades académicas, carreras y disciplinas (Hawes et al., 2017). En Chile, este proceso se cristalizó en la implementación del Sistema de Créditos Transferibles (SCT) que, junto con mover el foco desde los contenidos hacia las competencias

6 Las competencias se entienden como dimensiones de especialización con especificidad de dominio, tanto en su contenido como en su ejecución, es decir, consisten en habilidades y conocimientos situados, propios de los ámbitos disciplinares, y resultan fundamentales para un desempeño competente (Pellegrino \& Hilton, 2012). 
y actividades de aprendizaje necesarias para adquirirlas, visibilizó la importancia de contar con un perfil de egreso pertinente, entendido como una descripción de los resultados de aprendizaje al que tributa el plan de estudios (CRUCH, 2013).

En la misma línea, los centros educativos han promovido documentos institucionales para mejorar la calidad educativa, tales como modelos educativos o listados de competencias intencionadas institucionalmente, que orientan el desarrollo de los aprendizajes esperados. Además, se ha fomentado la aparición de programas e iniciativas de ingreso, nivelación, apoyo y acompañamiento de los estudiantes prioritarios, tanto en el nivel institucional local como en políticas de estado más generales (Santelices, Galleguillos, \& Catalán Avendaño, 2015; Treviño, Scheele, \& Flores, 2014). A esto se suma la ampliación, desarrollo y jerarquización de los organismos estatales semiautónomos de control que buscan evaluar, acreditar y promover la calidad educativa de las instituciones de educación superior, y que han restringido y fiscalizado en parte la tradicional autonomía universitaria y la libertad de mercado del sector privado (Lemaitre, 2015; Rama Vitale, 2006).

Estos procesos de innovación curricular, de mejoramiento institucional, de apoyo a los aprendizajes y de aseguramiento de la calidad están íntimamente vinculados y han ocupado un rol cada vez más visible y central en la dinámica de las instituciones de educación superior. Sin embargo, también han recibido críticas en tanto procesos de control externo y regímenes de accountability (evaluación de resultados, explicitación de competencias, etc.) que, eventualmente, podrían erosionar las relaciones de responsabilidad dentro de la comunidad educativa, ya que las vacían de contenido y las convierten en vínculos de mercado (Biesta, 2004).

En este contexto, la enseñanza y el aprendizaje de la lectura, la escritura y la oralidad en educación superior se ha posicionado como una necesidad, tanto para los denominados "estudiantes tradicionales" como para los nuevos perfiles estudiantiles de un sistema universitario 

SUPERIOR: CONTRASTES ENTRE INSTITUCIONES Y CARRERAS - F. Navarro, N. Ávila Reyes, L. Calle-Arango, A. Cortés Lagos

que ha experimentado procesos de expansión de la matrícula ${ }^{7}$ (Espinoza \& González, 2015). Además, ha presentado una ventana de oportunidad para el posicionamiento de la comunicación como un tópico de relevancia institucional (Adler-Kassner, 2008; Adler-Kassner \& Harrington, 2010), mediante la formalización de estrategias que buscan apoyar las trayectorias como lectores, escritores y oradores de los estudiantes de todas las áreas, con cursos generales transversales en el ingreso, cursos especializados de comunicación disciplinar, iniciativas de apoyo y asesoramiento colaborativo a la escritura a través del currículum, tutorías de escritura, etc. (Ávila Reyes, González-Álvarez, \& Peñaloza Castillo, 2013; Molina Natera, 2015; Thaiss, Bräuer, Carlino, Ganobcsik-Williams, \& Sinha, 2012).

Pese a este impulso desde las políticas educativas, y de la necesidad real de que estudiantes y graduados universitarios comprendan y produzcan formas esperadas, especializadas y altamente sofisticadas de lectura, escritura y oralidad académicas y profesionales, algunas investigaciones sugieren que la enseñanza de la comunicación académica y profesional aún forma parte del currículum oculto de las instituciones de educación superior (Moon, Ruggles Gere, \& Shultz, 2018). Más aún, este relegamiento incrementa las desigualdades ya existentes en el sistema educacional, pues la lectura, la escritura y la oralidad académicas forman parte del capital cultural y semiótico de los estudiantes con mayores privilegios (O'Shea, 2016; Zavala, 2019) y se utilizan como formas de evaluación y control de acceso o gatekeeping; en último término, son también un factor de exclusión (Lillis, 2001).

Por este motivo, es necesario preguntarse cuál es el vínculo entre los procesos recientes de innovación curricular por competencias y de acreditación institucional en el sistema de educación superior,

7 El concepto de "estudiante universitario no tradicional" suele asociarse a uno o más de los siguientes rasgos: perteneciente a minorías étnicas, de más de 25 años, de entornos socioeconómicos bajos, con participación temporal o de tiempo parcial en el mercado laboral, con discapacidad, primera generación universitaria dentro de su familia o con riesgo de abandono de estudios (Woolf, Zemits, Janssen, \& Knight, 2019). Se trata, en suma, de grupos sociales históricamente subrepresentados en educación superior, debido a barreras sociales, históricas e institucionales, y que se han incorporado en el marco de la masificación reciente del ingreso a la universidad. 
y la presencia de la comunicación escrita y oral en las competencias profesionales de egreso de las universidades, materializadas en los perfiles de egreso, en las competencias focalizadas y en los modelos educativos y formativos de las diferentes clases de instituciones del sistema. A su vez, es urgente indagar en las concepciones de lectura, escritura y oralidad que aparecen en esos documentos institucionales, así como la consistencia que presentan entre sí. Estas concepciones comprenden un conjunto situado de supuestos, conocimientos y valoraciones respecto del proceso de leer, escribir y comunicar oralmente (Difabio de Anglat, 2013), y resulta pertinente identificarlas en los documentos curriculares actuales pues influyen y moldean las prácticas y experiencias de aprendizaje (Aguilar Peña, Albarrán Vergara, Errázuriz Cruz, \& Lagos Paredes, 2016; Pozo, Scheuer, Mateos, \& del Puy Pérez Echeverría, 2006).

La presente investigación busca identificar la presencia, concepción y consistencia de la lectura, la escritura y la oralidad como competencias profesionales de egreso del sistema de educación superior chileno. A partir de una muestra de cinco carreras distintas en 10 instituciones chilenas universitarias que representan diversas variables de localización, selectividad, perfil institucional, misión, investigación y matrícula, se recolectaron y codificaron cualitativamente 50 perfiles de egreso públicos abreviados y 10 modelos educativos institucionales. La generación de investigación de base empírica sobre las formas en que el sistema de educación superior integra la lectura, la escritura y la oralidad en los perfiles curriculares de sus futuros graduados no solo contribuye con el conocimiento especializado e interdisciplinario sobre el tema, aún incipiente y parcial, sino que también ofrece información valiosa para orientar políticas públicas de innovación curricular y acreditación institucional.

\section{Lectura, escritura y oralidad en educación superior}

La comunicación académica se vincula directamente con competencias como el pensamiento crítico, la comunicación efectiva, la argumentación, el uso y evaluación de información y fuentes, la resolución de problemas, la colaboración, el "aprender a aprender", la 
176 LECTURA, ESCRITURA Y ORALIDAD EN PERFILES DE EGRESO DE EDUCACIÓN SUPERIOR: CONTRASTES ENTRE INSTITUCIONES Y CARRERAS - F. Navarro, N. Ávila Reyes, L. Calle-Arango, A. Cortés Lagos

autogestión y la creatividad (Pellegrino \& Hilton, 2012), las cuales se manifiestan por y a través de la lectura, la escritura y la oralidad. Estas competencias letradas, es decir, habilidades mediadas por la lectura, la escritura y la oralidad, se han transformado en elementos centrales para el desempeño profesional, la construcción del conocimiento social y la toma de decisiones en la esfera pública (Starke-Meyerring \& Paré, 2011).

La escritura desempeña una variedad de funciones en las trayectorias formativas en educación superior: es una herramienta epistémica y comunicativa, un medio de acreditación externa del saber y una oportunidad de desarrollo crítico, creativo y expresivo de los estudiantes (Navarro, 2018). Por su parte, la lectura incluye aspectos reconocibles, como la comprensión local y global de los textos y la realización de inferencias, pero también el desarrollo de competencias como la conciencia sintáctica o la autorregulación lectora (Sánchez Miguel, 2010), y la interpretación crítica de los contextos de producción de textos, la elaboración de opiniones y la construcción de identidades (Cassany, 2017). A su vez, la comunicación académica y científica ocurre en gran medida mediante intercambios orales (Rowley-Jolivet \& Carter Thomas, 2005), y la discusión, el debate o el trabajo colaborativo oral en pequeños grupos constituyen oportunidades para que los estudiantes de educación superior puedan percibirse como más capaces y sentir mayor motivación hacia las actividades de aprendizaje (Thaiss, Moloney, \& Chaozon-Bauer, 2016).

En suma, la lectura, la escritura y la oralidad no se restringen a una forma o a un estilo que media de forma transparente entre los contenidos, los pensamientos, las intenciones y los actores de la comunidad educativa. Deben entenderse como herramientas epistémicas que favorecen el aprendizaje y la construcción de conocimiento, con un rol protagónico del escritor y su aprendizaje. Tampoco constituyen una competencia básica y general que se desarrolla en etapas previas de escolarización o que puede restringirse a un curso aislado y remedial de argumentación o escritura especializada (Russell, 2002). Deben entenderse, en cambio, como competencias situadas en los marcos culturales y epistemológicos 
de las diferentes áreas disciplinares (Hyland, 2004). De esta forma, intervienen en un complejo proceso de aprendizaje, práctica, participación y enculturación que genera dinámicas de inclusión y exclusión (Ávila Reyes, Navarro, \& Tapia-Ladino, 2020; Lillis, 2001). En consecuencia, la lectura, la escritura y la oralidad académicas deberían formar parte del currículum en educación superior y, claro está, de las prácticas educativas efectivas en el aula. Esta curricularización podría materializarse como objetivos de enseñanza y aprendizaje; como dispositivos de enseñanza y evaluación; y como competencias profesionales de los futuros graduados universitarios. Esta curricularización es, además, esperable desde una perspectiva de innovación curricular por competencias transferibles y de alto nivel cognitivo que coloca al estudiante en el centro del proceso formativo.

\section{Instrumentos curriculares y comunicación académica}

Los documentos curriculares especifican los contenidos, competencias y objetivos que se busca que el estudiante aprenda, su secuencia y justificación, así como los criterios disciplinares, administrativos y pedagógicos de enseñanza, aprendizaje y evaluación. No son una mera lista de temas y competencias, sino que se centran en los aprendizajes esperados, en las acciones y pasos que debe realizar el estudiante, y en las responsabilidades del profesor para guiar ese proceso (Wiggins \& McTighe, 2005). Su función es clarificar los objetivos, contenidos y métodos de enseñanza y aprendizaje; brindar consistencia a la docencia a través de las distintas asignaturas y carreras; y orientar el proceso de enseñanza y aprendizaje dentro de la dinámica del aula (Newby, 2000). En suma, el currículum universitario formaliza y visibiliza los valores, expectativas, actividades y roles de estudiantes, docentes, cursos y carreras, en el contexto más amplio de las disciplinas y sistemas educativos formales (Stanny, Gonzalez, \& McGowan, 2015).

En este marco, la noción de currículum oculto resulta útil para dar cuenta de la divergencia entre lo que se declara haber enseñado y lo que los estudiantes efectivamente aprenden. Se compone de aquellos rasgos invisibilizados de la actuación en contextos de educación formal, como valores, actitudes y principios, e incluye, 
178 LECTURA, ESCRITURA Y ORALIDAD EN PERFILES DE EGRESO DE EDUCACIÓN SUPERIOR: CONTRASTES ENTRE INSTITUCIONES Y CARRERAS - F. Navarro, N. Ávila Reyes, L. Calle-Arango, A. Cortés Lagos

según Margolis, Soldatenko, Acker y Gair (2001), "normas, valores y sistemas de creencias situados en el currículum, la escuela y el aula, enseñadas a los estudiantes a través de rutinas diarias, contenidos curriculares y relaciones sociales", pero que "no son parte del contenido del currículum formal" (p. 6, traducción propia). Desde una perspectiva crítica, el currículum oculto reproduce la distribución inequitativa de oportunidades educativas en la sociedad y representa un obstáculo para la equidad social, ya que privilegia a los estudiantes cuyas familias poseen más capital cultural (Bourdieu, 1997) académico. Estos estudiantes mostrarán en clase rasgos altamente valorados —e incluso asociados a una mayor inteligencia y talento- - y tendrán más facilidad para decodificar las expectativas ocultas en entornos educativos. Esta descripción es particularmente válida respecto de los usos del lenguaje académico escrito y oral (Bernstein \& Henderson, 2003; Schleppegrell, 2004).

Un componente clave del currículum en educación superior es el perfil de egreso, documento que compromete una síntesis pública e institucional de las competencias y aprendizajes de finalización del proceso educativo específico por carreras en educación superior. Para Martínez Márquez (2015), el perfil de egreso "se construye en el conjunto de valores, rasgos, aptitudes y capacidad que se aspira a formar en el futuro profesional a través del proceso docente educativo que realiza la Universidad por encargo de la sociedad" (p. 217). El perfil de egreso constituye, de esta manera, una suerte de contrato — con supervisión estatal— entre universidades, profesores, estudiantes, empleadores y familias que especifica las competencias y conocimientos - tanto genéricos como disciplinarmente específicosque los estudiantes deberían haber desarrollado durante sus años formativos en educación superior (Spronken-Smith et al., 2015). No es casual que los perfiles de egreso aparezcan en un lugar prioritario en las entradas web y en la folletería de divulgación e inducción de las carreras universitarias.

En el caso de Chile, la ley 20129 de 2006 establece un sistema nacional de aseguramiento de la calidad en educación superior que enfatiza la importancia de que los procesos formativos sean coherentes con el perfil de egreso definido por cada universidad. 
El proceso de acreditación de carreras se basa en dos parámetros de evaluación: el perfil de egreso y los recursos y procesos que permiten asegurar su cumplimiento (cf. Ley Núm. 20129, 2006, artículo 28), es decir, desde el punto de vista legal, se entiende que la calidad educativa está estrechamente relacionada con el diseño adecuado de los perfiles de egreso y con la capacidad de las instituciones de implementar procesos formativos coherentes con ellos. A su vez, la Comisión Nacional de Acreditación (CNA) de Chile define el perfil de egreso como el "conjunto de conocimientos, competencias y actitudes que el/la estudiante de la carrera o programa habrá internalizado al momento de su titulación o graduación, y constituye el marco de referencia para la aplicación de los criterios de evaluación" (CNA, 2016, p. 7). De esta manera, la centralidad de los perfiles de egreso opera no solo en términos pedagógicos e institucionales, sino también en términos legales y de relación con la regulación estatal.

Por último, los perfiles de egreso suelen articularse con documentos institucionales generales o modelos, que especifican las competencias priorizadas e intencionadas por cada institución (llamadas competencias "sello", "genéricas", etc.) y la concepción pedagógica que sustenta el proceso formativo. Estos modelos educativos buscan orientar la práctica pedagógica institucional en relación con los énfasis y sellos culturales e históricos de cada universidad y su visión ética, social y profesional. Según Angulo, Espinoza y Angulo (2016), constituyen "el instrumento, por excelencia, que orienta el quehacer académico (currículo, calidad académica, perfil del egresado, perfil del ingresante, estrategias de enseñanza aprendizaje, responsabilidad social universitaria, investigación, evaluación del aprendizaje, etc.) y todas las actividades para su puesta en práctica y su mejora" (p. 165).

En suma, los programas, planes de estudio, perfiles de egreso y modelos educativos constituyen un acuerdo institucionalizado y explícito entre el estudiante, el personal docente y directivo, y la universidad, mediado por el Estado y sus organismos de fiscalización, y con compromisos con actores sociales diversos. Si bien es cierto que las dinámicas áulicas pueden modificar, ampliar u omitir elementos prescritos en los documentos curriculares, y no existe una 
180 LECTURA, ESCRITURA Y ORALIDAD EN PERFILES DE EGRESO DE EDUCACIÓN SUPERIOR: CONTRASTES ENTRE INSTITUCIONES Y CARRERAS - F. Navarro, N. Ávila Reyes, L. Calle-Arango, A. Cortés Lagos

correspondencia directa entre currículum y prácticas educativas, el diseño curricular es un medio de influir en la enseñanza y aprendizaje que ocurre en las instituciones. Por estos motivos, estudiar los documentos curriculares en educación superior es especialmente relevante para orientar los procesos de mejoramiento e innovación curricular y para informar a los organismos y procesos de acreditación del currículum universitario.

La mayor parte de las investigaciones sobre el rol de la lectura, la escritura y la oralidad en educación superior se ha llevado a cabo mediante entrevistas, encuestas, observación de clases y análisis textual de lo que los estudiantes deben leer o escribir (Gillet $\&$ Hammond, 2009; Melzer, 2009; Nesi \& Gardner, 2012). En contraste, es extremadamente raro hallar investigaciones empíricas, contrastivas y sistemáticas que aborden el lugar de la lectura, la escritura y la oralidad en el currículum prescrito a través de distintas carreras y etapas formativas en educación superior. Esta línea emergente de investigación, necesaria para comprender los procesos de innovación curricular, se ha valido principalmente del análisis cualitativo de contenidos en programas y en el contraste cuantitativo de ocurrencias a través de distintos contextos. Los perfiles de egreso se consideran en muy escasa medida.

Así, Graves, Hyland y Samuels (2010) rastrean tareas de escritura en 179 programas de curso de 17 carreras de una universidad de artes liberales canadiense y encuentran un promedio de 2.5 tareas escritas por curso, breves, frecuentemente sin objetivos claros, con bajo impacto en la calificación y poca orientación a los estudiantes. En una investigación similar, McGaughy et al. (2016) recopilan 2210 programas de 773 universidades públicas y privadas de Estados Unidos; hallan que la forma más frecuente de evaluación son los exámenes finales (60.1\%); las tareas predominantes son el ensayo en cursos de lenguaje (79.7\%) y ciencias sociales (34.3\%) y las actividades de laboratorio en ciencias (30.8\%); y el tipo de escritura más solicitado es la explicación. Por su parte, O’Day Nicolas y Annous (2013) rastrean, mediante análisis de contenidos, la enseñanza de la escritura a través del currículum en 30 programas de una facultad de Negocios del Líbano; detectan que la competencia escrita está 
prácticamente ausente de los resultados de aprendizaje y solo un 30\% de los cursos la solicitan.

En el ámbito latinoamericano, Feeney y Sosa (2011) analizan los programas y materiales didácticos de tres asignaturas universitarias en Argentina y observan la predominancia de una concepción remedial y reproductiva de la lectura y la escritura. En la misma universidad, Stagnaro y Navarro (2013) analizan el grado de consistencia entre las tareas solicitadas en Ingeniería Industrial y el perfil de egreso de la carrera; concluyen que existe cierta coherencia entre las incumbencias del graduado y las tareas ligadas a la toma de decisiones propias en el ejercicio de la práctica profesional, aunque con una presencia restringida de las competencias más complejas. Navarro (2016) analiza 20 programas de cuatro carreras humanísticas de una universidad estatal tradicional argentina. Encuentra que la lectura y la escritura no se curricularizan como objeto de enseñanza, sino solo como instrumentos de evaluación de los aprendizajes mediante exámenes y monografías.

Como puede observarse, las investigaciones sobre la presencia y concepción de la lectura, la escritura y la oralidad académicas en documentos curriculares de educación superior son aún incipientes, tanto a nivel regional como internacional, a pesar de su interés científico e institucional. Sin embargo, los hallazgos emergentes presentan una situación común para el rol de la escritura en el currículum de educación superior: las tareas de escritura suelen ser genéricas y carecen de orientación; no se asocian con resultados de aprendizaje; no incrementan sistemáticamente su complejidad a lo largo de las distintas etapas formativas; y tienen un impacto reducido en las calificaciones.

\section{Metodología}

Objetivo general y preguntas de investigación

El objetivo general de esta investigación es identificar la presencia, naturaleza y consistencia de las concepciones de la lectura, la escritura y la oralidad como competencias profesionales de egreso del sistema 
de educación superior chileno. Para cumplir con este propósito, se busca responder las siguientes preguntas de investigación:

1. ¿Cuál es la presencia de las competencias de lectura, escritura y oralidad en los perfiles de egreso públicos abreviados y en los modelos educativos de educación superior chilena?

2. ¿Cuál es el grado de consistencia curricular entre los documentos institucionales?

3. ¿Qué concepciones de la lectura, la escritura y la oralidad predominan y cómo se distribuyen?

\section{Muestra y corpus de estudio}

Se definió una muestra de 10 universidades chilenas, dentro de un sistema de educación superior que cuenta en la actualidad con 60 universidades (DIVESUP, 2019). Se consideró un conjunto de variables seleccionadas tanto de clasificaciones del Consejo Nacional de Educación (CNED) como discutidas en la bibliografía especializada (Améstica Rivas, Gaete Feres, \& Llinas-Audet, 2014; Bernasconi, 2006; Muñoz \& Blanco, 2013). Se determinaron las siguientes variables y definiciones operacionales: 
Tabla 1

Definición operacional de variables contextuales

\begin{tabular}{|c|c|c|}
\hline Variable & Valores & Definición \\
\hline Localización & $\begin{array}{l}\text { Metropolitana, } \\
\text { regional, } \\
\text { metropolitana- } \\
\text { regional }\end{array}$ & $\begin{array}{l}\text { Anclaje geográfico. La variable "metropolitana- } \\
\text { regional" describe instituciones con sedes para } \\
\text { la mayoría de sus carreras tanto en la región } \\
\text { metropolitana como en otras regiones del país. }\end{array}$ \\
\hline Selectividad & $\begin{array}{l}\text { Alta, media, sin } \\
\text { selectividad }\end{array}$ & $\begin{array}{l}\text { Las universidades que participan en el Sistema Único } \\
\text { de Admisión (SUA) corresponden a selectividad } \\
\text { "alta" y "media" (definida por rango de puntajes de la } \\
\text { Prueba de Selección Universitaria), y las que no, "sin } \\
\text { selectividad". }\end{array}$ \\
\hline $\begin{array}{l}\text { Perfil } \\
\text { institucional }\end{array}$ & $\begin{array}{l}\text { Estatal } \mathrm{CRUCH}^{8} \text {, } \\
\text { privada CRUCH, } \\
\text { privada adscrita } \\
\text { SUA, privada }\end{array}$ & $\begin{array}{l}\text { Antigüedad, organización administrativa y vinculación } \\
\text { estatal de las instituciones, según la clasificación } \\
\text { utilizada por el Consejo Nacional de Educación. }\end{array}$ \\
\hline Misión & Secular, religiosa & $\begin{array}{l}\text { Instituciones laicas o confesionales. Se considera que } \\
\text { una institución es "religiosa" si lo define así en su } \\
\text { nombre o si ofrece formación en teología. }\end{array}$ \\
\hline $\begin{array}{l}\text { Ranking de } \\
\text { investigación }\end{array}$ & $\begin{array}{l}\text { 1-10; 11-31; no } \\
\text { listada }\end{array}$ & $\begin{array}{l}\text { Perfil investigativo de la institución. Se utiliza el } \\
\text { Ranking Scimago (2019) para determinar la posición } \\
\text { relativa de cada institución. }\end{array}$ \\
\hline Tamaño & $\begin{array}{l}<10 \mathrm{~K} ; 10-20 \mathrm{~K} ; 20- \\
30 \mathrm{~K} ;>30 \mathrm{~K}\end{array}$ & $\begin{array}{l}\text { Matrícula total de estudiantes de pregrado }(K= \\
\text { 1000). Se utiliza información oficial de CNED } \\
\text { (2020). }\end{array}$ \\
\hline
\end{tabular}

A su vez, se definió un balance entre los distintos valores propuestos para lograr 10 clases o perfiles institucionales diversos, los cuales, por un lado, proporcionaron datos con un grado elevado de representatividad de la complejidad del sistema universitario en Chile y, por el otro, permitieron rastrear y contrastar resultados según rasgos institucionales a partir de elementos comunes que habilitan la comparación. En la Tabla 2 se detallan las clases de instituciones (se conserva la confidencialidad sobre la institución específica de la que se trata).

8 El Consejo de Rectores de las Universidades Chilenas (CRUCH), creado en 1954, es un organismo colegiado y autónomo que reúne 27 universidades chilenas en su mayoría consideradas "tradicionales" (creadas antes de 1981 o que se derivan de estas), incluyendo instituciones privadas y la totalidad de las instituciones estatales. Su misión es "procurar un mejor rendimiento y calidad de la enseñanza superior del país" (CRUCH, 2019). 
184 LECTURA, ESCRITURA Y ORALIDAD EN PERFILES DE EGRESO DE EDUCACIÓN SUPERIOR: CONTRASTES ENTRE INSTITUCIONES Y CARRERAS - F. Navarro, N. Ávila Reyes, L. Calle-Arango, A. Cortés Lagos

Tabla 2

Clases de instituciones del sistema de educación superior chileno consideradas en la muestra

\begin{tabular}{|c|c|c|c|c|c|c|}
\hline $\begin{array}{l}\text { Clase de } \\
\text { institución }\end{array}$ & Localización & Selectividad & $\begin{array}{c}\text { Perfil } \\
\text { institucional }\end{array}$ & Misión & $\begin{array}{l}\text { Ranking de } \\
\text { investigación }\end{array}$ & Tamaño \\
\hline Ul & Metropolitana & Alta & Estatal CRUCH & Secular & $1-10$ & $>30 \mathrm{~K}$ \\
\hline U2 & Metropolitana & Alta & $\begin{array}{l}\text { Privada } \\
\text { CRUCH }\end{array}$ & Religiosa & $1-10$ & $20-30 \mathrm{~K}$ \\
\hline U3 & Regional & Media & Estatal CRUCH & Secular & No listada & $<10 \mathrm{~K}$ \\
\hline U4 & Regional & Media & $\begin{array}{l}\text { Privada } \\
\text { CRUCH }\end{array}$ & Religiosa & $11-30$ & $10-20 \mathrm{~K}$ \\
\hline U5 & Regional & Alta & $\begin{array}{l}\text { Privada } \\
\text { CRUCH }\end{array}$ & Secular & $1-10$ & $20-30 \mathrm{~K}$ \\
\hline U6 & Metropolitana & Media & $\begin{array}{c}\text { Privada } \\
\text { adscrita SUA }\end{array}$ & Religiosa & No listada & $<10 \mathrm{~K}$ \\
\hline U7 & $\begin{array}{c}\text { Regional } \\
\text {-Metropolitana }\end{array}$ & Media & $\begin{array}{c}\text { Privada } \\
\text { adscrita SUA }\end{array}$ & Secular & $11-30$ & $>30 \mathrm{~K}$ \\
\hline U8 & Metropolitana & Media & $\begin{array}{c}\text { Privada } \\
\text { adscrita SUA }\end{array}$ & Religiosa & $1-10$ & $<10 \mathrm{~K}$ \\
\hline U9 & $\begin{array}{c}\text { Regional } \\
\text {-Metropolitana }\end{array}$ & No selectiva & Privada & Religiosa & $11-30$ & $20-30 \mathrm{~K}$ \\
\hline U10 & $\begin{array}{c}\text { Regional } \\
\text {-Metropolitana }\end{array}$ & No selectiva & Privada & Secular & No listada & $20-30 \mathrm{~K}$ \\
\hline
\end{tabular}

A partir de estas 10 instituciones, se seleccionaron cinco carreras de pregrado que permitieran dar cuenta de una diversidad de planes de estudios, facultades, áreas disciplinares y ámbitos de desempeño profesional, y que formaran parte de la oferta académica de las 10 universidades estudiadas: 1) Pedagogía en Educación Básica; 2) Ingeniería Civil Industrial; 3) Derecho; 4) Enfermería; 5) Ingeniería Comercial.

Constituida la muestra, se recolectaron dos tipos de documentos: perfiles de egreso públicos abreviados y modelos educativos para cada una de estas instituciones y carreras de pregrado. Los perfiles se encuentran disponibles en la web institucional de las universidades en el marco de su oferta curricular y están destinados al estudiante, su familia y su comunidad; por este motivo, pueden ser parcialmente diferentes de los perfiles utilizados de forma oficial en la creación de carreras o en los procesos de acreditación. Por otro lado, se recolectaron los modelos educativos o formativos de cada institución, que incluyen competencias designadas y focalizadas por cada universidad de extensión variable. Si bien los documentos recogidos son públicos y se encuentran disponibles de manera 
libre, se escribió un correo a las autoridades de las universidades investigadas (directores de carrera, directores de pregrado o equivalentes) consultando si existían documentos más actualizados que los ofrecidos en la web, para garantizar la pertinencia del corpus recolectado.

\section{Procedimientos de análisis}

El corpus se clasificó de acuerdo con las variables institucionales y se codificó con asistencia del software de análisis cualitativo QSR NVivo Pro12. Para guiar el trabajo de análisis, se elaboró un libro de códigos cualitativos con definiciones de categorías, ejemplos y criterios ${ }^{9}$. Las competencias se identificaron a partir de procesos verbales (formas finitas, no finitas y nominalizaciones) en los que los estudiantes ocupan el rol de agentes.

La codificación se basó en dos categorías. La primera categoría es competencia letrada, constituida por los códigos excluyentes implícita y explícita (con los subcódigos comunicación, lectura, escritura, oralidad, L2 y digital), según están definidos en la Tabla 3. La segunda categoría es concepción y se utiliza para la clasificación de competencias letradas explícitas a partir de dos códigos simultáneos: contexto y conocimiento, con sus respectivos subcódigos expuestos en la Tabla 4.

9 Para colaborar con la transparencia, consistencia y replicabilidad del análisis, el libro de códigos se encuentra disponible en el siguiente enlace y puede ser utilizado para otras investigaciones: https://www.doi.org/10.13140/RG.2.2.31141.93923 
186 LECTURA, ESCRITURA Y ORALIDAD EN PERFILES DE EGRESO DE EDUCACIÓN SUPERIOR: CONTRASTES ENTRE INSTITUCIONES Y CARRERAS - F. Navarro, N. Ávila Reyes, L. Calle-Arango, A. Cortés Lagos

\section{Tabla 3}

Definiciones operacionales para la categoría competencia letrada

\begin{tabular}{lll}
\hline Código & Subcódigo & Definición operativa y ejemplo \\
\hline Implícitas $\mathrm{n} / \mathrm{a}$ & Competencia en la que, sin referirse a la lectura, escritura u \\
& oralidad, es imprescindible y directo el uso de elementos letrados. \\
& "Analizar problemas o situaciones, al interior de una organización \\
& sector o país, relacionadas con el ámbito económico" (ID35, Ing \\
& Comercial).
\end{tabular}

Explícitas Competencia que incluye términos directamente referentes a la lectura, la escritura o la oralidad.

Comunicación Subcódigo excluyente para denominaciones generales que no especifican la competencia comunicativa de la que se trata.

"Se comunica de forma efectiva" (ID17, Ing. Industrial, énfasis añadido).

Lectura Modo de uso de la lengua. Subcódigo no excluyente con los otros modos.

"Comprender ideas principales de discursos orales y escritos en situaciones cotidianas y del mundo profesional" (ID79, Modelo educativo, énfasis añadido).

Escritura Modo de uso de la lengua. Subcódigo no excluyente con los otros modos.

"Exponiendo a través de un lenguaje oral y escrito" (ID34, Enfermería, énfasis añadido).

Oralidad Modo de uso de la lengua. Subcódigo no excluyente con los otros modos.

"Exponiendo a través de un lenguaje oral y escrito" (ID34, Enfermería, énfasis añadido).

L2 Subcódigo excluyente que remite a otras lenguas en cualquiera de las cuatro competencias.

"Desarrollo de habilidades comunicacionales y comprensivas suficientes en la lengua inglesa" (ID78, Modelo educativo, énfasis añadido).

Digital Subcódigo excluyente que remite a la literacidad digital.

"Uso de las tecnologías de la información y comunicación" (ID80, Modelo educativo, énfasis añadido). 
Tabla 4

Definiciones operacionales para la categoría concepción sobre competencia letrada explícita

\begin{tabular}{|c|c|c|}
\hline Código & Subcódigo & Definición operativa y ejemplo \\
\hline \multirow[t]{3}{*}{ Contexto } & & $\begin{array}{l}\text { Contextualización de la competencia en una disciplina o } \\
\text { situación. }\end{array}$ \\
\hline & Situada & $\begin{array}{l}\text { La competencia se vincula a un contexto específico. } \\
\text { Subcódigo excluyente. } \\
\text { "Elaborar textos de los géneros académicos y profesionales } \\
\text { propios de su área, incorporando debidamente diferentes } \\
\text { fuentes de información" (ID79, Modelo educativo). }\end{array}$ \\
\hline & Básica & $\begin{array}{l}\text { La competencia se plantea como habilidad general y } \\
\text { transversal a todo contexto. Subcódigo excluyente. } \\
\text { "Habilidades comunicativas en español" (ID77, Modelo } \\
\text { educativo). }\end{array}$ \\
\hline \multicolumn{3}{|c|}{ Conocimiento } \\
\hline & Epistémica & $\begin{array}{l}\text { La competencia se plantea como construcción de saberes } \\
\text { nuevos a partir de distintas fuentes y contenidos. Subcódigo } \\
\text { excluyente. }\end{array}$ \\
\hline & & $\begin{array}{l}\text { "Usa estratégicamente la información y las tecnologías } \\
\text { asociadas a ésta, comunicándola de forma efectiva en un } \\
\text { contexto organizacional para contribuir a la generación de } \\
\text { valor y éxito" (ID27, Ing. Industrial). }\end{array}$ \\
\hline & Reproductiva & $\begin{array}{l}\text { La competencia se centra en la comunicación de } \\
\text { conocimientos o saberes previos. Subcódigo excluyente. } \\
\text { "Se persigue que el estudiante desarrolle un adecuado sentido } \\
\text { de comunicación y fluidez en la lengua materna" (ID78, } \\
\text { Modelo educativo). }\end{array}$ \\
\hline
\end{tabular}

Para garantizar la consistencia en el análisis cualitativo que sustenta los resultados de la investigación, se realizó un proceso de calibración y revisión entre los cuatro investigadores que incluyó un análisis exploratorio y un 20\% de doble codificación, con un índice Kappa de Cohen de confiabilidad de 0.87, considerado un acuerdo óptimo (Fleiss, Levin, \& Cho Paik, 2003). Finalmente, se realizó una auditoría de toda la codificación para evitar falsos positivos y conseguir mayor consistencia global.

Posteriormente, se cuantificaron las ocurrencias de la codificación cualitativa, se creó un índice de ocurrencias cada 1000 palabras para permitir comparabilidad y se vincularon con las variables de instituciones y carreras. Esto permitió establecer patrones que asociaron categorías con el tipo de documento, las carreras y los distintos valores o rasgos de las clases de instituciones. Finalmente, se realizaron pruebas estadísticas con el fin de determinar si había diferencias estadísticamente significativas entre las recurrencias. 
188 LECTURA, ESCRITURA Y ORALIDAD EN PERFILES DE EGRESO DE EDUCACIÓN SUPERIOR: CONTRASTES ENTRE INSTITUCIONES Y CARRERAS - F. Navarro, N. Ávila Reyes, L. Calle-Arango, A. Cortés Lagos

\section{Resultados y discusión}

Presencia, tipos y consistencia de competencias letradas

Para aportar evidencias respecto de la presencia de la lectura, la escritura y la oralidad en documentos curriculares, es pertinente analizar la media de ocurrencias de competencias letradas explícitas e implícitas por perfil de egreso en el sistema de educación superior chileno. Un primer hallazgo es que, en general, la presencia de competencias letradas es baja: se encontró una media de seis competencias por perfil de egreso. Dada la extensión variable de los documentos curriculares, se proyectó la presencia de estas competencias cada 1000 palabras, índice en el que se expresa la mayor parte de los resultados reportados (ver Figura 1). Llama particularmente la atención las universidades con menor presencia de competencias letradas en sus perfiles: la U1 y la U5, que corresponden a universidades llamadas "tradicionales", pertenecientes al CRUCH, con alta selectividad y ambas ubicadas en el rango de 1 a 10 en investigación. Por otro lado, las universidades que exhiben una mayor presencia de competencias letradas en perfiles de egreso son la U9, institución privada, religiosa, no selectiva y con sedes en diversas regiones del país, seguida por la U4, perteneciente al CRUCH, religiosa, medianamente selectiva y regional; ambas se ubican en el rango 11 a 30 en investigación.

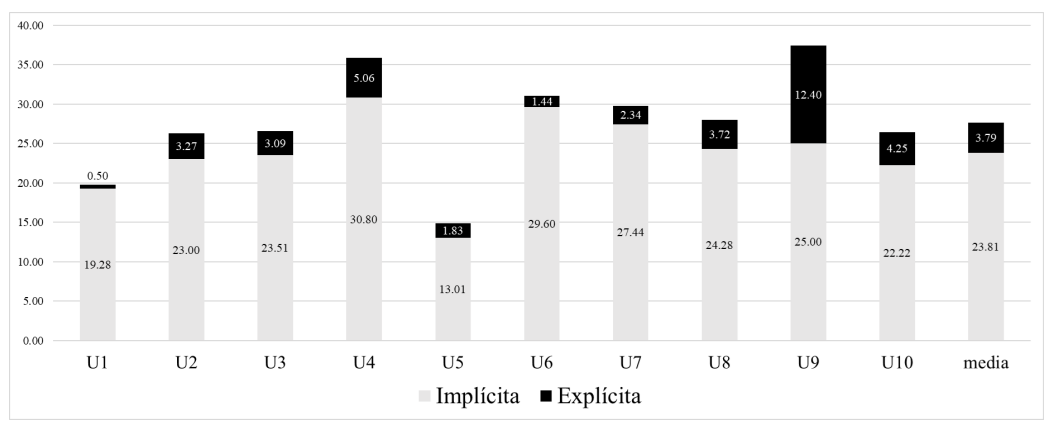

Figura 1.

Competencias letradas implícitas y explícitas en perfiles de egreso por universidad cada 1000 palabras 
Se aplicó la prueba no paramétrica de Kruskal-Wallis para estimar si la distribución de las competencias letradas, implícitas y explícitas, variaba por institución, pero no se encontraron diferencias estadísticamente significativas. En otras palabras, la tendencia de los perfiles en general es hacia una baja presencia de competencias letradas y, en particular, a la invisibilización de estas por medio de competencias que implícitamente requieren de la lectura, la escritura y la oralidad para lograrse.

$\mathrm{Al}$ analizar los perfiles de egreso por carrera, se mantiene una distribución uniforme de una muy baja frecuencia de competencias explícitas y una media más alta de 24 competencias implícitas cada 1000 palabras por perfil (ver Figura 2). La carrera de Pedagogía en Educación Básica se ubica debajo de esta media, con unas 16.2 competencias cada 1000 palabras, mientras que Ingeniería Comercial es la carrera con mayor presencia de competencias letradas implícitas, con unas 30 competencias cada 1000 palabras. Al aplicar la prueba no paramétrica de Kruskal-Wallis, se observa que la diferencia en la distribución de las competencias implícitas de los perfiles entre carreras es estadísticamente significativa $(\mathrm{H}(4)=9.993 ; p>.041)$, y las pruebas post-hoc de Mann Whitney indican que esta diferencia es estadísticamente significativa entre Pedagogía y todas las carreras $(p<.023)$, excepto Derecho. No se encontraron otros pares con diferencias significativas.

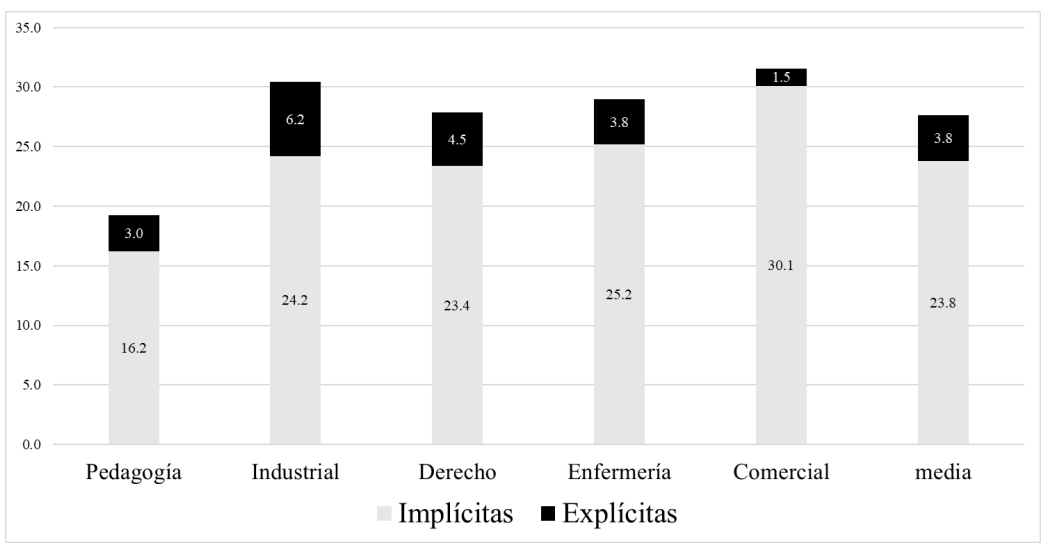

Figura 2.

Competencias letradas implícitas y explícitas en perfiles de egreso por carrera cada 1000 palabras 
190 LECTURA, ESCRITURA Y ORALIDAD EN PERFILES DE EGRESO DE EDUCACIÓN SUPERIOR: CONTRASTES ENTRE INSTITUCIONES Y CARRERAS - F. Navarro, N. Ávila Reyes, L. Calle-Arango, A. Cortés Lagos

En la carrera de Pedagogía, las competencias letradas implícitas incluyen el trabajo con otros en la comunidad educativa, por ejemplo "trabajar en equipo" (ID36); aplicación de dispositivos educativos, como "competencias para diseñar, planificar, implementar y evaluar procesos pedagógicos y para actualizarlos y perfeccionarlos fundadamente a través de la investigación" (ID26), y la reflexión para la formación continua: "[capacidad de] reflexionar e indagar acerca de su quehacer docente" (ID31); "utilizar la investigación para desarrollar las competencias que faciliten mejorar los procesos y resultados de su enseñanza" (ID21). En todos estos ejemplos se puede reconocer una serie de complejas habilidades letradas subyacentes. Así, por ejemplo, para "diseñar" un proceso pedagógico es necesario buscar y leer teoría; leer y reinterpretar el currículum; redactar objetivos de aprendizaje; escribir una planificación o secuencia didáctica; escribir y redactar materiales educativos adaptados a la edad y nivel de los estudiantes; comunicar oralmente mediante interacciones complejas en aula los contenidos, etc. Por contraste, las escasas competencias letradas explícitas de esta carrera presentan habilidades mucho más genéricas, sin detalle y de menor complejidad, como por ejemplo en segunda lengua ("el manejo del idioma inglés a nivel elemental para las dos primeras menciones", ID16) o mediante el uso de tecnologías de la información y la comunicación ("uso de tecnologías educativas como transversales a la formación", ID01).

En Ingeniería Comercial, la carrera con mayor presencia de competencias en su conjunto, las competencias letradas implícitas se agrupan en torno al análisis y desarrollo de soluciones, y la creación de conocimientos y negocios para situaciones y problemas, como en ser "capaces de analizar situaciones complejas, proponer soluciones y mejoras" (ID05), o "ser creador de conocimientos científicos" (ID25); el diseño y seguimiento de planes de negocios; y el liderazgo de equipos y procesos y la interacción con otros: "lidiar efectivamente con los desafíos de dirigir organizaciones y personas" (ID10). Al igual que en los ejemplos previos, se observa un contraste entre la profundidad y diversidad de las operaciones discursivas asociadas a estas competencias implícitas, como las habilidades de comunicación oral de alto nivel requeridas para lidiar con los desafíos de dirigir organizaciones, y la vaguedad y generalidad de las competencias letradas explícitas. 
Estas incluyen menciones básicas y genéricas, como "capacidad de comunicación, con manejo de tecnología y del idioma inglés" (ID35).

Además de representar habilidades de bajo nivel, los perfiles de egreso muestran una media de menos de una competencia explícita oral o escrita (4 cada 1000 palabras). Ninguna carrera supera las ocho competencias letradas explícitas cada 1000 palabras. La mayor cantidad de competencias explícitas se concentra en Ingeniería Civil Industrial, seguida de Enfermería, pero, al aplicar la prueba no paramétrica de Kruskal-Wallis, no se observa diferencia estadísticamente significativa en la distribución de las competencias explícitas entre carreras.

Dentro de esta baja incidencia, la Figura 3 ilustra la distribución porcentual de las 35 competencias explícitas observadas en los 50 perfiles (algunas codificadas en más de un tipo). La competencia explícita más frecuente es también la que por definición resulta más genérica: comunicación (media $=37.8 \% ; n=17$ ), predominante en Ing. Industrial; seguida de competencias digitales (media $=20 \% ; n=$ 9), frecuente en la carrera de Pedagogía; oralidad (media $=15.6 \% ; n$ = 7), predominante en Derecho; y L2 (media $=13.3 \% ; n=6$ ), predominante en Pedagogía. Las competencias explícitas de escritura y lectura tienen escasa presencia, con apenas cinco competencias de escritura y solo una de lectura a lo largo de los 50 perfiles (tres de ellas en Derecho).

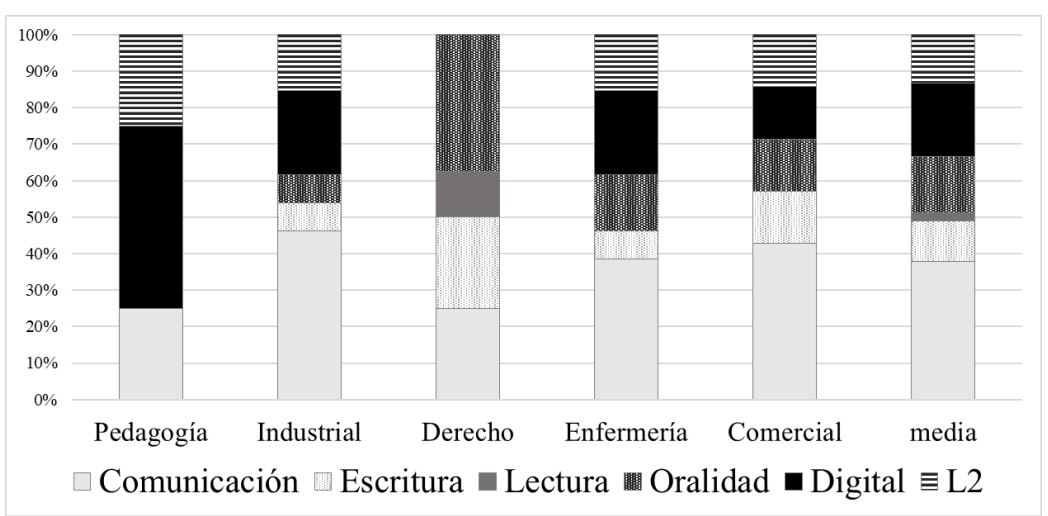

Figura 3.

Tipos de competencias letradas explícitas en perfiles de egreso por carrera en porcentaje 
192 LECTURA, ESCRITURA Y ORALIDAD EN PERFILES DE EGRESO DE EDUCACIÓN SUPERIOR: CONTRASTES ENTRE INSTITUCIONES Y CARRERAS - F. Navarro, N. Ávila Reyes, L. Calle-Arango, A. Cortés Lagos

Al observar la presencia de competencias letradas en los modelos educativos, como se presenta en la Figura 4, un primer elemento que vale la pena destacar es que las competencias implícitas totales son levemente menores que las explícitas, a diferencia de lo que ocurre en los perfiles. Esto sugiere que los modelos presentan las competencias letradas de manera más explícita e intencionada que los perfiles (al ser géneros discursivos distintos, no es posible comparar entre perfiles y modelos las ocurrencias cada 1000 palabras). Las universidades 1, 2, 6, 9 y 10 muestran menos de 10 ocurrencias en total de competencias letradas agregadas, si bien no se hallan rasgos comunes en sus perfiles institucionales.

Respecto de la distribución de los tipos de competencias explícitas intencionadas, dos competencias son predominantes y con presencia en la mayoría de los modelos: $L 2$ (media $=30.8 \%$, presente en 7 modelos; $n=33$ ) y comunicación (media $=21.5 \%$, presente en 7 modelos; $n=23$ ), seguidas de escritura (media $=17.8 \%$, presente en 6 modelos; $\mathrm{n}=19$ ), oralidad (media $=15.9 \%$, presente en 5 modelos; $n=10$ ), digital (media $=9.3 \%$, presente en 4 modelos; $n=10) \mathrm{y}$, prácticamente inexistente, lectura (media $=4.7 \%$, presente en 2 modelos; $n=5$ ), como muestra la Figura 5 . Es decir, coinciden con los perfiles en priorizar la comunicación y olvidar la lectura, pero se diferencian en la visibilidad de la escritura y las segundas lenguas, más frecuentes en modelos.

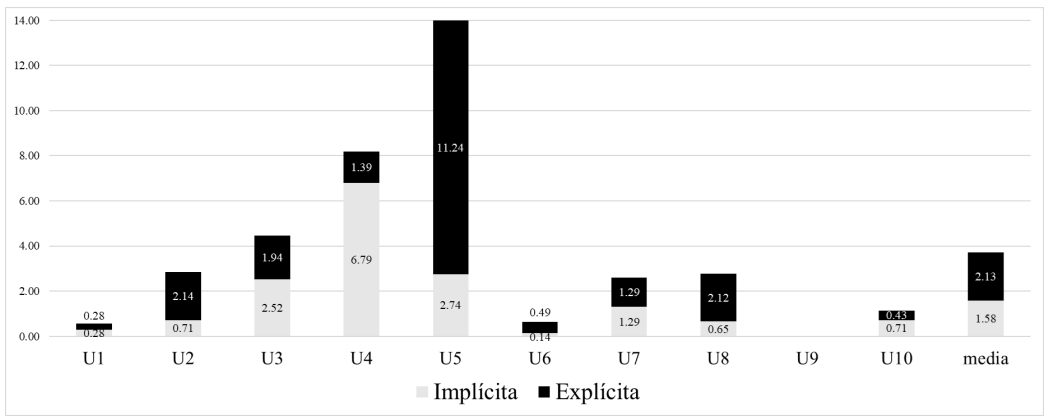

Figura 4.

Competencias letradas implícitas y explícitas en modelos educativos por universidad cada 1000 palabras 


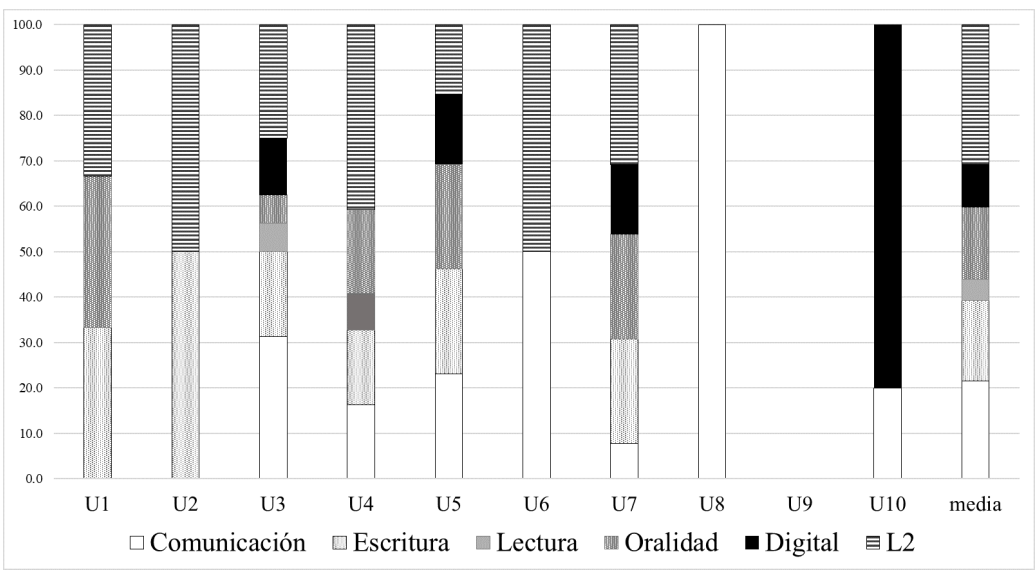

Figura 5.

Tipos de competencias letradas explícitas en modelos educativos por universidad en porcentaje

Por último, al analizar en qué medida la presencia de las competencias letradas en los perfiles de cada institución es consistente con lo declarado en los modelos educativos, emergen algunas dinámicas que vale la pena considerar: la U5 es la institución que más competencias presenta en su modelo, pero, al mismo tiempo, la que menos competencias letradas incluye en sus perfiles de egreso. Esta inconsistencia sugiere que el trabajo realizado en el modelo educativo no ha permeado a los niveles de carrera. Al mismo tiempo, destaca el caso de la U9, que presenta una cantidad importante de competencias en sus perfiles, pero ninguna en el modelo educativo, lo que da cuenta de una ausencia de focalización en estas competencias en el nivel central. Entre las universidades con mayor consistencia se encuentran la U4, que posee el mayor promedio de competencias en sus perfiles y los índices más altos en su modelo (luego de la U5), y la U1, que es una de las más bajas en competencias por perfil y también por modelo, documento en que presenta menos de una competencia letrada cada 1000 palabras.

\section{Predominancia y distribución de concepciones sobre competencias letradas explícitas}

La reconstrucción de las concepciones subyacentes en las competencias letradas explícitas muestra que estas tienden a ser de 
194 LECTURA, ESCRITURA Y ORALIDAD EN PERFILES DE EGRESO DE EDUCACIÓN SUPERIOR: CONTRASTES ENTRE INSTITUCIONES Y CARRERAS - F. Navarro, N. Ávila Reyes, L. Calle-Arango, A. Cortés Lagos

carácter básico y, especialmente, reproductivo. En otras palabras, lectura, escritura y oralidad se conciben fundamentalmente como formas de transmitir conocimiento $(85.7 \% ; n=30)$, no de crearlo, $\mathrm{y}$, en la mayoría de los casos $(57.1 \% ; n=20)$, sin una especificidad retórica contextualizada en los distintos ámbitos disciplinares y profesionales. La Tabla 5 permite explorar las concepciones letradas subyacentes por carreras a lo largo de los 50 perfiles de egreso.

Tabla 5

Concepciones sobre la lectura, la escritura y la oralidad en perfiles de egreso por carrera en porcentajes

\begin{tabular}{cccccc}
\hline & \multicolumn{2}{c}{ Conocimiento } & \multicolumn{2}{c}{ Contexto } \\
\hline \multirow{6}{*}{ Carreras } & Reproductiva & Epistémica & Básica & Situada \\
& Pedagogía $(n=4)$ & $75 \%$ & $25 \%$ & $75 \%$ & $25 \%$ \\
& Industrial $(n=10)$ & $70 \%$ & $30 \%$ & $50 \%$ & $50 \%$ \\
& Derecho $(n=4)$ & $75 \%$ & $25 \%$ & $50 \%$ & $50 \%$ \\
& Enfermería $(n=11)$ & $100 \%$ & $0 \%$ & $36 \%$ & $64 \%$ \\
& Comercial $(n=6)$ & $100 \%$ & $0 \%$ & $100 \%$ & $0 \%$ \\
Media $(n=35)$ & $85.7 \%$ & $14.3 \%$ & $57.1 \%$ & $42.9 \%$ \\
\hline
\end{tabular}

Al contrastar por carreras respecto de la dimensión contexto, para el total de competencias explícitas codificadas en los perfiles de cada carrera, se verifica que Enfermería es la carrera con una concepción más situada (vinculada a un contexto específico de uso) de las competencias letradas $(64 \%, n=7)$, seguida por Ingeniería Civil Industrial $(50 \%, n=5)$ y Derecho $(50 \%, n=2)$, como arroja la Tabla 5. En estos casos, las competencias letradas explícitas se entienden como parte de las situaciones propias del quehacer disciplinar, como puede verse en los ejemplos que aporta la Tabla 6. Finalmente, se destaca Ingeniería Comercial como la carrera con menos competencias explícitas situadas $(n=0)$, en contraste con su rasgo de carrera con más competencias implícitas de la muestra.

Para la dimensión de conocimiento, las competencias reproductivas (aquellas que entienden la lectura, la escritura y la oralidad como formas de transmitir contenidos previos) prevalecen en Enfermería e Ingeniería Comercial. En tanto, las concepciones epistémicas (aquellas que entienden el lenguaje como forma de crear conocimientos) son muy escasas y casi inexistentes a lo largo de la muestra. 
Tabla 6

Ejemplos de concepciones sobre la lectura, la escritura y la oralidad en perfiles de egreso y modelos

\begin{tabular}{|c|c|c|c|}
\hline \multicolumn{2}{|c|}{ Conocimiento } & \multicolumn{2}{|r|}{ Contexto } \\
\hline Reproductiva & Epistémica & Básica & Situada \\
\hline $\begin{array}{l}\text { "Aportando } \\
\text { habilidades } \\
\text { necesarias para } \\
\text { comunicar sus } \\
\text { ideas de manera } \\
\text { efectiva" (ID40, } \\
\text { Ing. Comercial). }\end{array}$ & $\begin{array}{l}\text { "Es capaz de razonar, } \\
\text { argumentar y usar las } \\
\text { fuentes para identificar } \\
\text { y resolver problemas } \\
\text { jurídicos, en forma } \\
\text { oral y escrita" (ID08, } \\
\text { Derecho). }\end{array}$ & $\begin{array}{l}\text { "Manejo de un } \\
\text { segundo idioma" } \\
\text { (ID81, Modelo } \\
\text { educativo). } \\
\text { "Posee } \\
\text { habilidades } \\
\text { interpersonales y }\end{array}$ & $\begin{array}{l}\text { "Desarrollar habilidades } \\
\text { comunicativas en el } \\
\text { idioma inglés, para } \\
\text { desenvolverse en } \\
\text { situaciones cotidianas, } \\
\text { laborales y académicas" } \\
\text { (ID34, Enfermería). }\end{array}$ \\
\hline $\begin{array}{l}\text { "Capacidad de } \\
\text { comunicación } \\
\text { oral y escrita" } \\
\text { (ID76, Modelo } \\
\text { educativo). }\end{array}$ & $\begin{array}{l}\text { "Manejo de recursos } \\
\text { de la información } \\
\text { (TIC): Capacidad para } \\
\text { utilizar de manera } \\
\text { ética y eficaz las } \\
\text { fuentes de información } \\
\text { y herramientas } \\
\text { tecnológicas } \\
\text { disponibles, en la } \\
\text { gestión y procesamiento } \\
\text { de información } \\
\text { relevante y atingente } \\
\text { para el logro de un } \\
\text { objetivo académico y } \\
\text { comunicacional" (ID82, } \\
\text { Modelo educativo). }\end{array}$ & $\begin{array}{l}\text { comunicacionales"' } \\
\text { (ID24, } \\
\text { Enfermería). }\end{array}$ & $\begin{array}{l}\text { "'Posee habilidad para } \\
\text { comunicarse por escrito } \\
\text { de forma efectiva tanto } \\
\text { en español como en } \\
\text { inglés, especialmente } \\
\text { en temas relativos a su } \\
\text { profesión" (ID37, Ing. } \\
\text { Industrial). }\end{array}$ \\
\hline
\end{tabular}

Finalmente, al analizar los modelos por universidades, pese a que estos tienen una mayor cantidad de competencias explícitas en comparación con las implícitas, en las primeras se repite la tendencia a las competencias reproductivas $(92.5 \% ; n=86)$, en cuanto al conocimiento, y básicas $(69.9 \% ; n=65)$, en cuanto al contexto. Solo hay una excepción, que corresponde al modelo educativo de la U4 (CRUCH, religiosa, selectividad mediana, ranking investigación 11-30), que presenta 44 competencias, 13.6\% de las cuales son epistémicas y $52 \%$, situadas. Este análisis permite concluir que la concepción de escritura en los modelos educativos es abrumadoramente reproductiva y básica, como se aprecia en la Tabla 7, a pesar de que explicitan las competencias letradas en mayor medida que los perfiles de egreso. 
196 LECTURA, ESCRITURA Y ORALIDAD EN PERFILES DE EGRESO DE EDUCACIÓN SUPERIOR: CONTRASTES ENTRE INSTITUCIONES Y CARRERAS - F. Navarro, N. Ávila Reyes, L. Calle-Arango, A. Cortés Lagos

Tabla 7

Concepciones sobre la lectura, la escritura y la oralidad en modelos educativos por universidad en porcentajes

\begin{tabular}{cccccc}
\hline & & \multicolumn{2}{c}{ Conocimiento } & \multicolumn{2}{c}{ Contexto } \\
\hline & & Reproductiva & Epistémica & Básica & Situada \\
& $\mathrm{U} 1(n=3)$ & $100 \%$ & $0 \%$ & $100 \%$ & $0 \%$ \\
$\mathrm{U} 2(n=2)$ & $100 \%$ & $0 \%$ & $100 \%$ & $0 \%$ \\
$\mathrm{U} 3(n=13)$ & $100 \%$ & $0 \%$ & $100 \%$ & $0 \%$ \\
& $\mathrm{U} 4(n=44)$ & $86.4 \%$ & $13.6 \%$ & $48 \%$ & $52 \%$ \\
Instituciones & $\mathrm{U} 5(n=10)$ & $100 \%$ & $0 \%$ & $90 \%$ & $10 \%$ \\
& $\mathrm{U} 6(n=2)$ & $100 \%$ & $0 \%$ & $100 \%$ & $0 \%$ \\
& $\mathrm{U} 7(n=10)$ & $90 \%$ & $10 \%$ & $80 \%$ & $20 \%$ \\
& $\mathrm{U} 8(n=4)$ & $100 \%$ & $0 \%$ & $75 \%$ & $25 \%$ \\
& $\mathrm{U} 9(n=0)$ & $0 \%$ & $0 \%$ & $0 \%$ & $0 \%$ \\
& $\mathrm{U} 10(n=5)$ & $100 \%$ & $0 \%$ & $75 \%$ & $25 \%$ \\
Media $(n=93)$ & & $92.5 \%$ & $7.5 \%$ & $69.9 \%$ & $30.1 \%$ \\
\hline
\end{tabular}

\section{Conclusiones y proyecciones}

Esta investigación ha conseguido determinar la presencia relativa de la comunicación académica en las competencias profesionales de egreso, las concepciones subyacentes con que se presenta y su grado de adecuación curricular con otros documentos institucionales. La amplitud del muestreo en términos de perfiles institucionales y de ámbitos disciplinares permite hacer afirmaciones que, si bien no resultan directamente generalizables, sí pueden señalar rasgos del sistema de educación superior chileno en su conjunto.

Los resultados indican que la lectura, la escritura y la oralidad tienen una presencia reducida en los perfiles de egreso universitarios. Su presencia se invisibiliza en competencias letradas implícitas y de alta demanda cognitiva, como "analizar problemas", lo que resta centralidad a la enseñanza y aprendizaje explícitos e intencionados de las competencias letradas que permiten llevar a cabo esos procesos.

La presencia de competencias letradas explícitas es abrumadoramente baja, por igual en todas las carreras, con un promedio de menos de una competencia explícita por perfil analizado. Al analizar los tipos de competencias explícitas, predominan las competencias "comunicativas", genéricas por definición, mientras 
que la escritura y, en particular, la lectura casi no tienen presencia explícita en los perfiles. Al analizar la concepción subyacente, se entienden como competencias básicas y, sobre todo, reproductivas; salvo en Enfermería, en que prevalecen las concepciones situadas en la práctica profesional, e Ingeniería Civil Industrial, que se destaca por tener la mayor cantidad de competencias de carácter epistémico.

Respecto de los modelos educativos, se observa una tendencia a explicitar las competencias letradas pues, al contrario que en los perfiles, las competencias explícitas superan a las implícitas. Sin embargo, se repite la tendencia a referirse a competencias genéricas de comunicación, la mayoría reproductivas y básicas. En efecto, en toda la muestra solo hay dos universidades que presentan competencias de carácter epistémico en sus modelos (U4 y U7), lo que señala que en el currículum chileno de educación superior no se promueve la lectura, la escritura y la oralidad como formas de construir el conocimiento de las disciplinas. Estas dos universidades están, además, entre las que mayor cantidad de competencias letradas exhiben en sus perfiles, junto con las U6 y U9. A su vez, algunas instituciones son especialmente inconsistentes respecto de las competencias letradas en sus perfiles de egreso y en sus marcos educativos generales (U5 y U9), otras no focalizan en competencias letradas en ninguno de estos tipos de documentos (U1), mientras que otras ofrecen un foco en competencias letradas en ambos tipos de documentos curriculares (U4).

A partir de esto, vale destacar un último hallazgo: las universidades con menor presencia de las competencias letradas en sus perfiles (U1 y U5) son instituciones tradicionales, altamente selectivas y de investigación. Al parecer, asumen, erróneamente, que la escritura es una habilidad básica que los estudiantes que reciben, altamente preparados, ya deberían dominar. Al contrario, aquellas con mayor presencia de competencias en sus perfiles son universidades de mediana selectividad y que se encuentran en proceso de aumentar su producción investigativa (U4 y U9). Esto permite inferir que existe una preocupación institucional por la temática, aunque, por la predominancia de concepciones poco informadas, puede deberse a teorías implícitas del déficit de los estudiantes que reciben. 
198 LECTURA, ESCRITURA Y ORALIDAD EN PERFILES DE EGRESO DE EDUCACIÓN SUPERIOR: CONTRASTES ENTRE INSTITUCIONES Y CARRERAS - F. Navarro, N. Ávila Reyes, L. Calle-Arango, A. Cortés Lagos

Estos resultados confirman y profundizan hallazgos parciales reportados por la escasa bibliografía que vincula lectura, escritura, oralidad y currículum en educación superior. En un contexto en que algunas instituciones y carreras están moviéndose hacia un mayor compromiso con la incorporación de competencias letradas en sus documentos curriculares, con la organización curricular por competencias y con la inclusión de estudiantes con trayectorias y entornos más diversos, es urgente que los procesos de innovación y acreditación de carreras e instituciones estén informados por una concepción contemporánea de la lectura, la escritura y la oralidad como competencias retóricas complejas y situadas que requieren un lugar explícito en la formación de los futuros graduados universitarios.

En este sentido, este trabajo intenta sistematizar evidencia para hacer uso de las exigencias de los regímenes de accountability como una oportunidad para la mejora educativa. La existencia de perfiles que instan a explicitar los focos formativos, y la constatación de la reducida presencia de las competencias letradas en ellos, permite defender frente a los directivos la necesidad de su instanciación curricular. Al mismo tiempo, la visión institucional predominantemente reproductiva y básica de la escritura que se desprende de este análisis promueve la adopción de estrategias remediales aisladas, como cursos o talleres, relegando las complejidades de la enseñanza y el aprendizaje disciplinar de la escritura al currículum oculto. Por ello, es necesario repensar estratégicamente los perfiles para plantear prácticas democratizantes que cambien el discurso sobre la responsabilidad de formar en escritura a los futuros profesionales.

Un caso en que esto se hace particularmente patente es la carrera de Pedagogía en Educación Básica, en cuyos perfiles las competencias letradas se hallan significativamente disminuidas, casi ausentes. Si consideramos el actual contexto, en que la Evaluación Nacional Docente, mandatada por la Ley 20903, muestra sistemáticos bajos desempeños en escritura de los egresados de esta carrera, el hecho de que el contrato formativo mínimo no explicite la centralidad de estas habilidades resulta un despropósito. 
Finalmente, en estudios futuros, debe indagarse en qué medida los perfiles de egreso cortos y públicos, destinados a los interesados en inscribirse en una carrera, se corresponden con los perfiles extendidos y administrativos, presentes en los decretos de creación de carreras, pero de difícil acceso para la comunidad educativa. A su vez, otros estudios deberían completar estas evidencias a partir de su contraste con las prácticas efectivas de aula, junto con las concepciones y creencias, de docentes y estudiantes acerca de las definiciones curriculares halladas.

\section{Referencias}

Adler-Kassner, L. (2008). The activist WPA: Changing stories about writing and writers. Logan, Utah: Utah State University Press.

Adler-Kassner, L., \& Harrington, S. (2010). Responsibility and composition's future in the twenty-first century: Reframing "accountability". College Composition and Communication, 62(1), 73-99.

Aguilar Peña, P., Albarrán Vergara, P., Errázuriz Cruz, M. C., \& Lagos Paredes, C. (2016). Teorías implícitas sobre los procesos de escritura: relación de las concepciones de estudiantes de Pedagogía Básica con la calidad de sus textos. Estudios Pedagógicos, 42(3), 7-26. doi: http://dx.doi. org/10.4067/S0718-07052016000400001

Améstica Rivas, L., Gaete Feres, H., \& Llinas-Audet, X. (2014). Segmentación y clasificación de las universidades en Chile: desventajas de inicio y efectos de las políticas públicas de financiamiento. Ingeniare. Revista Chilena de Ingeniería, 22(3), 384-397. doi: http://dx.doi.org/10.4067/ S0718-33052014000300009

Angulo H., P., Espinoza B., J. A., \& Angulo A., P. J. (2016). Educación universitaria de calidad con formación integral y competencias profesionales. Horizonte de la Ciencia, 6(11), 159-167. doi: https:// doi.org/10.26490/uncp.horizonteciencia.2016.11.237

Ávila Reyes, N., González-Álvarez, P., \& Peñaloza Castillo, C. (2013). Creación de un programa de escritura en una universidad chilena: estrategias para promover un cambio institucional. Revista Mexicana de Investigación Educativa, 18(57), 537-560.

Ávila Reyes, N., Navarro, F. \& Tapia-Ladino, M. (2020). Identidad, voz y agencia: claves para una enseñanza inclusiva de la escritura en la universidad. Education Policy Analysis Archives, 28(98). http://epaa.asu.edu/ojs/article/view/4722 
Bernasconi, A. (2006). Does the affiliation of universities to external organizations foster diversity in private higher education? Chile in comparative perspective. Higher Education, 52(2), 303-342. doi: https://doi.org/10.1007/s10734-004-5326-8

Bernstein, B., \& Henderson, D. (2003). Social class differences in the relevance of language to socialization. In Class, codes and control 2: Applied studies towards a sociology of language (pp. 22-43). London: Routledge \& Kegan Paul.

Biesta, G. (2004). Education, accountability, and the ethical demand: Can the democracy potential of accountability be regained? Educational Theory, 54(3), 233-250. doi: https://doi.org/10.1111/j.00132004.2004.00017.x

Bourdieu, P. (1997). Capital cultural, escuela y espacio social. México: Siglo XXI Editores.

Cassany, D. (2017). Lectura crítica: qué, cómo, dónde y por qué. En P. H. J. Quintanilla \& A. Valle (Eds.), El desarrollo de las competencias básicas en los Estudios Generales (pp. 74-101). Lima: PUCP.

CNA. (2016). Glosario de Pregrado. Santiago de Chile: Comisión Nacional de Acreditación. Recuperado de https://www.cnachile.cl/Paginas/ Acreditacion-Pregrado.aspx

CNED. (2020). Matrícula Sistema de Educación Superior (2019). Recuperado de https://www.cned.cl/indices/matricula-sistema-de-educacion-superior

CRUCH. (2013). Manual para la implementación del Sistema de Créditos Académicos Transferibles SCT-Chile. Santiago de Chile: CRUCH.

CRUCH. (2019, 11 noviembre). ¿Qué es el Consejo de Rectores? Recuperado de https://www.consejoderectores.cl/preguntas-frecuentes

Difabio de Anglat, H. (2013). Evaluación de las concepciones de escritura académica en doctorandos en educación. Revista Electrónica Actualidades Investigativas en Educación, 13(3), 1-21. doi: https://doi. org/10.15517/aie.v13i3.12040

DIVESUP. (2019, enero). Instituciones y carreras reconocidas por el MINEDUC. Recuperado de https://www.ayudamineduc.cl/ficha/instituciones-ycarreras-reconocidas-por-el-mineduc-5

Espinoza, O., \& González, L. E. (2015). Equidad en el Sistema de Educación Superior de Chile: acceso, permanencia, desempeño y resultados. En A. Bernasconi (Ed.), La educación superior de Chile. Transformación, desarrollo y crisis (pp. 517-580). Santiago de Chile: Ediciones UC. 
Feeney, S., \& Sosa, Y. (2011). El análisis de los programas y materiales de apoyo a la enseñanza de las tres asignaturas del CAU. En N. Gluz (Ed.), Admisión a la universidad y selectividad social. Cuando la democratización es más que un problema de "ingresos" (pp. 105-126). Los Polvorines: UNGS.

Fleiss, J. L., Levin, B., \& Cho Paik, M. (2003). Statistical methods for rates and proportions. New Jersey: Wiley. Third edition.

Gillett, A., \& Hammond, A. (2009). Mapping the maze of assessment. An investigation into practice. Active Learning in Higher Education, 10(2), 120-137. doi: https://doi.org/10.1177/1469787409104786

Graves, R., Hyland, T., \& Samuels, B. M. (2010). Undergraduate writing assignments: An analysis of syllabi at one Canadian college. Written Communication, 27(3), 293-317. doi: https://doi. org/10.1177/0741088310371635

Hawes, G., Rojas-Serey, A. M., Espinoza, M., Oyarzo, S., Castillo-Parra, S., Castillo, M., \& Romero, L. (2017). Desarrollo de una matriz conceptual para la innovación curricular en profesiones de la salud. Revista Médica de Chile, 145, 1193-1197. doi: http://dx.doi.org/10.4067/s003498872017000901193

Hyland, K. (2004). Disciplinary cultures, texts and interactions. En Disciplinary discourses. Social interactions in academic writing (pp. 1-19). Michigan: The University of Michigan Press.

Kreber, C. (2009). The modern research university and its disciplines: The interplay between contextual and context-transcendent influences on teaching. In C. Kreber (Ed.), The university and its disciplines: Teaching and learning within and beyond disciplinary boundaries (pp. 19-31). New York: Routledge.

Lehesvuori, S., Ramnarain, U., \& Viiri, J. (2018). Challenging transmission modes of teaching in science classrooms: Enhancing learnercentredness through dialogicity. Research in Science Education, 48(5), 1049-1069. doi: http://dx.doi.org/10.1007/s11165-016-9598-7

Lemaitre, M. J. (2015). Aseguramiento de la calidad: una política y sus circunstancias. En A. Bernasconi (Ed.), La educación superior de Chile. Transformación, desarrollo y crisis (pp. 295-344). Santiago de Chile: Ediciones UC.

Ley Núm. 20129 (2006, 17 noviembre). Recuperado de https://www.leychile. cl/Navegar?idNorma $=255323$

Lillis, T. (2001). Student writing. Access, regulation, desire. London \& New York: Routledge. 
202 LECTURA, ESCRITURA Y ORALIDAD EN PERFILES DE EGRESO DE EDUCACIÓN SUPERIOR: CONTRASTES ENTRE INSTITUCIONES Y CARRERAS - F. Navarro, N. Ávila Reyes, L. Calle-Arango, A. Cortés Lagos

Margolis, E., Soldatenko, M., Acker, S., \& Gair, M. (2001). Peekaboo. En E. Margolis (Ed.), The hidden curriculum in higher education (pp. 1-19). New York \& London: Routledge.

Martínez Márquez, L. E. (2015). Evaluación del perfil de egreso: primer paso para la reformulación del currículum. CPU-e, Revista de Investigación Educativa, 21, 210-221.

McGaughy, C., Hopper-Moore, G., Fukuda, E., Phillips, R., Rooseboom, J., \& Chadwick, K. (2016). Understanding entry-level courses in American institutions of higher education. Educational Policy Improvement Center. Recuperado de https://eric.ed.gov/?id=ED571632

Melzer, D. (2009). Writing assignments across the curriculum: A national study of college writing. College Composition and Communication, 61(2), 240-261.

Molina Natera, V. (Ed.) (2015). Panorama de los centros y programas de escritura en Latinoamérica. Santiago de Cali: Pontificia Universidad Javeriana.

Moon, A., Ruggles Gere, A., \& Shultz, G. V. (2018). Writing in the STEM classroom: Faculty conceptions of writing and its role in the undergraduate classroom. Science Education, 102(5), 1007-1028. doi: https://doi.org/10.1002/sce.21454

Muñoz, M., \& Blanco, C. (2013). Una taxonomía de las universidades chilenas. Calidad en la Educación, 38, 181-213. doi: https://doi. org/10.4067/S0718-45652013000100005

Navarro, F. (2016). La lectura y la escritura en carreras de humanidades: análisis de roles y procesos en programas de asignaturas. En M. Vedda \& J. P. Moris (Eds.), Actas del VI Congreso Internacional de Letras (pp. 1201-1210). Buenos Aires: Universidad de Buenos Aires.

Navarro, F. (2018). Más allá de la alfabetización académica: las funciones de la escritura en educación superior. En M. A. Alves \& V. Iensen Bortoluzzi (Eds.), Formação de Professores: Ensino, linguagens e tecnologias (pp. 1349). Porto Alegre: Editora Fi.

Nesi, H., \& Gardner, S. (2012). Genres across the disciplines. Student writing in higher education. Cambridge: CUP.

Newby, D. (2000). Syllabus and curriculum design. In M. Byram (Ed.), Routledge encyclopedia of language teaching and learning (pp. 590-594). London \& New York: Routledge.

O’Day Nicolas, M., \& Annous, S. (2013). Assessing WAC elements in business syllabi. Business Communication Quarterly, 76(2), 172-187. doi: https:// doi.org/10.1177/1080569912471709 
O'Shea, S. (2016). Avoiding the manufacture of "sameness": First-in-family students, cultural capital and the higher education environment. Higher Education, 72, 59-78. doi: https://doi.org/10.1007/s10734015-9938-y

Pellegrino, J. W., \& Hilton, M. L. (Eds.). (2012). Education for life and work. Developing transferable knowledge and skills in the 21st century. Washington DC: The National Academies Press.

Pozo, J. I., Scheuer, N., Mateos, M., \& del Puy Pérez Echeverría, M. (2006). Las teorías implícitas sobre el aprendizaje y la enseñanza. En J. I. Pozo, N. Scheuer, M. del Puy Pérez Echeverría, M. Mateos, E. Martín, \& M. de la Cruz (Eds.), Nuevas formas de pensar la enseñanza y el aprendizaje (pp. 95-132). Barcelona: Graó.

Rama Vitale, C. (2006). La tercera reforma de la educación superior en América Latina y el Caribe: masificación, regulaciones e internacionalización. Revista Educación y Pedagogía, XVIII(46), 13-24.

Reimers, F., \& Chung, C. K. (2016). Teaching and learning for the twentyfirst century: Educational goals, policies, and curricula from six nations. Cambridge, Massachusetts: Harvard Education Press.

Rowley-Jolivet, E., \& Carter-Thomas, S. (2005). Genre awareness and rhetorical appropriacy: Manipulation of information structure by NS and NNS scientists in the international conference setting. English for Specific Purposes, 24, 41-64. doi: https://doi.org/10.1016/j. esp.2003.09.003

Russell, D. (2002). Writing in the academic disciplines: A curricular history $\left(2^{\text {nd }}\right.$ ed.). Carbondale, IL: Southern Illinois University Press.

Sánchez Miguel, E. (2010). La lectura en el aula. Qué se hace, qué se debe hacer y qué se puede hacer. Barcelona: Graó.

Santelices, M. V., Galleguillos, P., \& Catalán Avendaño, X. (2015). El acceso y la transición a la universidad en Chile. En A. Bernasconi (Ed.), La educación superior de Chile. Transformación, desarrollo y crisis (pp. 581627). Santiago de Chile: Ediciones UC.

Schleppegrell, M. J. (2004). The language of schooling. A functional linguistics perspective. Mahwah, NJ: Lawrence Erlbaum.

Scimago. (2019). Scimago institutions rankings - higher education - Chile research rank. Recuperado de https://www.scimagoir.com/index.php

Spronken-Smith, R., Bond, C., McLean, A., Frielick, S., Smith, N., Jenkins, M., $\&$ Marshall, S. (2015). Evaluating engagement with graduate outcomes across higher education institutions in Aotearoa/ New Zealand. Higher 
204 LECTURA, ESCRITURA Y ORALIDAD EN PERFILES DE EGRESO DE EDUCACIÓN SUPERIOR: CONTRASTES ENTRE INSTITUCIONES Y CARRERAS - F. Navarro, N. Ávila Reyes, L. Calle-Arango, A. Cortés Lagos

Education Research \& Development, 34(5), 1014-1030. doi: https://doi. org/10.1080/07294360.2015.1011098

Stagnaro, D., \& Navarro, F. (2013). Consignas de evaluación en la carrera de Ingeniería Industrial: articulaciones entre la formación universitaria y la inserción profesional. En L. Natale (Ed.), El semillero de la escritura. Las tareas escritas a lo largo de tres carreras de la UNGS (pp. 71-91). Los Polvorines: UNGS.

Stanny, C., Gonzalez, M., \& McGowan, B. (2015). Assessing the culture of teaching and learning through a syllabus review. Assessment $E$ Evaluation in Higher Education, 40(7), 898-913. doi: https://doi.org/1 0.1080/02602938.2014.956684

Starke-Meyerring, D., \& Paré, A. (2011). The roles of writing in knowledge societies: Questions, exigencies, and implications for the study and teaching of writing. In D. Starke-Meyerring, A. Paré, N. Artemeva, M. Horne, \& L. Yousoubova (Eds.), Writing in knowledge societies (pp. 3-28). Fort Collins, Colorado: The WAC Clearinghouse \& Parlor Press.

Thaiss, C., Bräuer, G., Carlino, P., Ganobcsik-Williams, L., \& Sinha, A. (Eds.). (2012). Writing programs worldwide: Profiles of academic writing in many places. West Lafayette, Indiana: Parlor Press \& WAC Clearinghouse.

Thaiss, C., Moloney, K., \& Chaozon-Bauer, P. (2016). "Freeing students to do their best": Examining writing in first-year seminars. Across the Disciplines, 13(4), 1-14.

Treviño, E., Scheele, J., \& Flores, S. M. (2014). Beyond the test score: A mixed methods analysis of a college access intervention in Chile. Journal of Mixed Methods Research, 8(3), 255-265. doi: https://doi. org/10.1177/1558689814527940

Wiggins, G., \& McTighe, J. (2005). Understanding by design. Alexandria, VA: Association for Supervision and Curriculum Development.

Woolf, S., Zemits, B., Janssen, A., \& Knight, S. (2019). Supporting resilience in first year of university: Curriculum, consideration and cooperation. Journal of Academic Language E Learning, 13(1), A108-A123.

Zavala, V. (2019). Justicia sociolingüística para los tiempos de hoy. Íkala, revista de lenguaje y cultura, 24(2), 343-359. doi: http://dx.doi. org/10.17533/udea.ikala.v24n02a09

Recibido: 15/11/2019

Aceptado: 06/04/2020 